\title{
A reform too late and a "redisorganisation" too far
}

\author{
Kamran Abbasi international editor, The BMJ
}

The World Health Organization is at the forefront of our efforts to defeat Ebola virus disease. Preventing and treating communicable diseases were the making of WHO as an international organisation capable of delivering successful health campaigns. Historically, Africa has preoccupied WHO more than any other continent. Recent pandemic threats, from avian flu to Middle East respiratory syndrome, readied WHO for the current crisis that now threatens 15 countries (doi:10.1136/bmj. g6305).

Ebola, on the face of it, plays to WHO's strengths. WHO might demonstrate the benefits of its focus on health information and strengthening of health systems. Instead, Ebola is firming up the case for the organisation's critics, who argue that WHO has failed in its governance role and is increasingly a bystander in the world's health affairs.

An internal WHO document leaked to news agencies lends credence to accusations by the charity Médecins Sans Frontières that WHO was slow to respond to Ebola. Its experts failed to report developments in a timely manner or to appreciate their importance, bureaucracy stopped $\$ 500000$ reaching the response effort, and doctors who wanted to help were delayed by visa problems (doi:10.1136/bmj.g6390). WHO says it is currently preoccupied with fighting the Ebola epidemic and will investigate the criticisms once the outbreak is contained.

Any review is likely to damage WHO, which must seize the opportunity to redefine its purpose and its limits. The challenge of building the capacity of health systems - the central weakness in the response to Ebola-is complex but sits at the core of WHO's responsibilities. If confirmed, any failings by WHO will increase calls for reform. WHO remains an organisation with great potential to help nations improve health outcomes but is crippled by continuing political and financial woes.
Health system challenges aren't confined to Africa, of course. UK primary care is stretched and may even be at breaking point. Prime Minister David Cameron's promise to deliver a seven day service has raised alarm. Recent reviews concluded that England's GPs were too few and too stressed, Veronica Wilkie writes (doi:10.1136/bmj.g6274). Our editorialist Stephen Gillam questions how a seven day service can be achieved against a backdrop of increasing workforce shortages and demoralisation (doi:10.1136/bmj.g6268). The former health secretary Andrew Lansley's NHS reorganisation, which underestimated costs and overestimated financial upsides, is now described by Downing Street sources as "unintelligible gobbledygook" and the worst mistake of the coalition government, as Kieran Walshe describes (doi:10.1136/bmj.g6340). Goodwill towards future "redisorganisation" is elusive.

The experience of the state of Oregon is that expanding services, in this case insurance coverage, requires primary care to be bolstered, otherwise efforts to improve the health system will fail (doi:10.1136/bmj.g5976). How else can we offer, for example, the better care services that are needed for young people who self harm (doi:10.1136/bmj.g6204; doi:10.1136/ bmj.g5954)? Or, attend to people who present with a history of fever of $>38^{\circ} \mathrm{C}$ within the past 21 days and who have recently come from an area affected by Ebola?

On the last point, at least you can turn to our full coverage of the Ebola outbreak (thebmj.com/ebola), which includes a briefing for primary and secondary care staff that summarises the latest guidance, including that from WHO (doi:10.1136/bmj. g6288).

Follow Kamran Abbasi on Twitter @KamranAbbasi

Cite this as: BMJ 2014;349:96400

๑ BMJ Publishing Group Ltd 2014 